\title{
PENGGUNAAN JOBSHEET INTERAKTIF DALAM PRAKTIKUM ANALISIS RANGKAIAN LISTRIK DAN ELEKTRONIKA
}

\author{
Fitri Nopitasari, Wawan Purnama \\ Program Studi Pendidikan Teknik Elektro FPTK UPI \\ Jalan Dr. Setiabudhi 207 Bandung 40154 \\ Telp. (022) 2013163 Ext. 3410 \\ E-mail : fitri.thomas@gmail.com
}

\begin{abstract}
Abstrak : Semakin berkembang pesatnya ilmu pengetahuan dan teknologi pada era globalisasi ini mengakibatkan perubahan terhadap keadaan yang terjadi di segala bidang. Penggunaan Jobsheet Interaktif dalam praktikum dilakukan sebagai upaya inovasi belajar untuk meningkatkan tingkat penguasaan siswa dalam melaksanakan praktikum dengan benar, gaya belajar yang berbeda, praktikum disertai jobsheet yang menggunakan komputer dengan cara yang mudah akan membangkitkan semangat siswa dalam belajar, meningkatkan perhatian siswa terhadap materi serta meningkatkan efektivitas dalam melaksanakan praktikum. Penelitian menggunakan metode deskriptif kuantitatif dengan subyek nya yaitu kelas X EPU di SMK Negeri 12 Bandung Tahun Pelajaran 2011/2012 dengan jumlah populasi sampel 32 siswa. Pengumpulan data dilakukan dengan angket, tes objektif pilihan ganda dan tes praktikum. Pengolahan data dilakukan dengan menghitung uji kelinieran dan keberartian regresi, koefisien korelasi dan koefisien determinasi dengan bantuan Microsoft Excel 2007. Hasil perhitungan angket memberikan gambaran umum bagaimana respon siswa dalam penggunaan jobsheet interaktif, sedangkan dari test objektif dan tes praktikum menunjukkan tingkat penguasaan dan hasil belajar siswa. Hasil perhitungan koefisien korelasi dan koefisien determinasi, respon siswa dalam penggunaan Jobsheet Interaktif (variabel X) memiliki pengaruh positif terhadap tingkat penguasaan siswa dalam melaksanakan praktikum (variabel Y) dengan taraf sedang/ cukup.
\end{abstract}

Kata Kunci : jobsheet, kuantitatif, praktikum.

Abstract : The rapid growth of science and technology in the era of globalization is resulting in changes to the circumstances in all areas. Interactive Jobsheet utilization in the lab performed as learning innovation efforts to improve students' level of proficiency in performing lab work correctly, different learning styles, accompanied jobsheet that uses a computer in a way that will easily evoke the spirit of the students in learning, improving students' attention to the subject material and to improve the effectiveness in implementing practical. Research using quantitative descriptive method with the subject is the first class of Aircfraft Eelectronic at Vocational High School 12 Bandung Academic Year 2011/2012, with a population sample of 32 students. Data was collected through questionnaires, multiple-choice objective test and lab test. Data processing is performed by calculating the linearity test and the significance of regression, correlation coefficients and coefficients of determination with the help of Microsoft Excel 2007. The results of the calculations provide an overview of how the questionnaire responses of students in the interactive jobsheet utilization, while the objective test and lab tests showed the level of mastery and student learning outcomes. The results of the calculation of the correlation coefficient and the coefficient of determination, the response of the students in the Interactive Jobsheet utilization (variable $\mathrm{X}$ ) has a positive influence on students' level of proficiency in performing lab (variable Y) with standard medium / fairly

Keywords: jobsheet, quantitative, lab. 


\section{PENDAHULUAN}

Pendidikan merupakan proses yang kompleks, namun kompleksitasnya selalu seiring dengan perkembangan manusia. Melalui pendidikan pula berbagai aspek kehidupan dikembangkan melalui proses belajar dan pembelajaran. Berbagai masalah dalam proses belajar perlu diselaraskan dan distabilkan agar kondisi belajar tercipta sesuai dengan tujuan yang ingin dicapai serta dapat diperoleh seoptimal mungkin. Untuk melengkapi komponen belajar dan pembelajaran di sekolah, sudah seharusnya guru memanfaatkan media atau alat bantu yang mampu merangsang pembelajaran secara efektif dan efisien. Ketika praktikum, dalam memvisualkan suatu bahan ajar terkadang mengalami hambatan yang disebabkan oleh keterbatasan pengajar, peralatan, alat, bahan, biaya dan sebagainya di mana proses penyampaian informasi atau transfer ilmu tidak cukup hanya dengan penyampaian secara verbal (ceramah). Terkadang pengajar sebagai penyampai informasi kepada siswa kurang bisa menciptakan suasana belajar yang menarik dan kondusif.

Berdasarkan hasil observasi pada saat peneliti melakukan Program Latihan Profesi (PLP) di SMK Negeri 12 Bandung yang berlangsung selama satu semester, ternyata tingkat penguasaan siswa dalam melaksanakan praktikum dengan benar di SMKN 12 Bandung masih dikategorikan rendah. Keaktifan siswa dalam proses pembelajaran masih kurang. Selama praktikum dilaksanakan, siswa cenderung lebih ribut dan tidak memperhatikan intruksi dari guru. Rendahnya hasil belajar siswa tersebut menunjukkan rendahnya pemahaman siswa terhadap pelajaran. Hal ini disebabkan karena pembelajaran didominasi dengan metode ceramah yang berpusat pada guru. Guru lebih aktif dalam kegiatan pembelajaran sebagai pemberi pengetahuan bagi siswa, komunikasi yang terjadi yaitu komunikasi satu arah, dimana gurulah yang aktif memberikan materi pelajaran kepada siswa, sementara siswa cenderung tidak memperhatikan guru. Setelah melakukan sedikit perbincangan bersama beberapa siswa, didapat beberapa alasan mengapa siswa tidak memperhatikan guru ketika belajar. Salah satunya yaitu, siswa merasa bosan dan membutuhkan suasana belajar yang efektif dan menarik. 
Penelitian ini bertujuan untuk mengetahui respon siswa terhadap penggunaan jobsheet interaktif dalam praktikum, serta hubungan dari penggunaan jobsheet interaktif (varibel $\mathrm{X}$ ) dengan tingkat penguasaan siswa dalam melaksanakan praktikum dengan benar (variabel Y).

\section{METODE}

Pemilihan metode penelitian yang didasarkan pada permasalahanpermasalahan yang aktual, objek yang diteliti, variable yang diteliti, serta tujuan penulisannya. Permasalahan yang aktual dalam penelitian ini, berlangsung sebagaimana adanya. Masalah dalam penelitian ini memerlukan pengukuran untuk mengetahui pengaruh suatu variable. Mengacu pada permasalah yang aktual dalam penelitian ini, berlangsung sebagaimana adanya pada waktu penelitian sedang dilaksanakan maka metode penelitian yang digunakan dalam penelitian ini adalah metode dekriptif kuantitatif.

\section{HASIL PENELITIAN}

Pengumpulan data hasil penelitian dilakukan dengan menggunakan instrumen penelitian berupa angket dan tes yang telah di uji kualitasnya dengan pengujian validitas, reliabilitas, daya pembeda serta tingkat kesukarannya. Instrumen dibuat penulis berdasarkan materi dan teori-teori yang relevan dengan fokus penelitian. Angket disusun berkaitan dengan teori dan landasan filosofis tentang respon siswa terhadap penggunaan jobsheet interaktif, sedangkan tes objektif dan tes praktikum dibuat berdasarkan silabus, rencana pelaksanaan pembelajaran (RPP), dan jobsheet praktikum.

Gambar 1 menunjukkan rekapitulasi hasil validitas instrumen untuk mempermudah mengetahui jumlah instumen yang valid dan tidak valid. Tingkat reliabilitas dihitung menggunakan rumus Alfa Cronbach dengan hasill perhitungan uji reliabilitas variabel X sebesar 4,9 dan variabel Y sebesar 0,76. Hasilnya diperoleh

$r_{11}$ dibandingkan dengan nilai dari $r_{\text {tabel }}$, jika $r_{11} \geq r_{\text {tabel }}$ maka instrumen tersebut reliabel. Pada taraf kepercayaan $99 \%$ nilai $r_{\text {tabel }}$ untuk 30 responden adalah sebesar 0,463, karena $r_{11} \geq r_{\text {tabel }}$ maka instrument tersebut dapat dikatakan reliabel. 


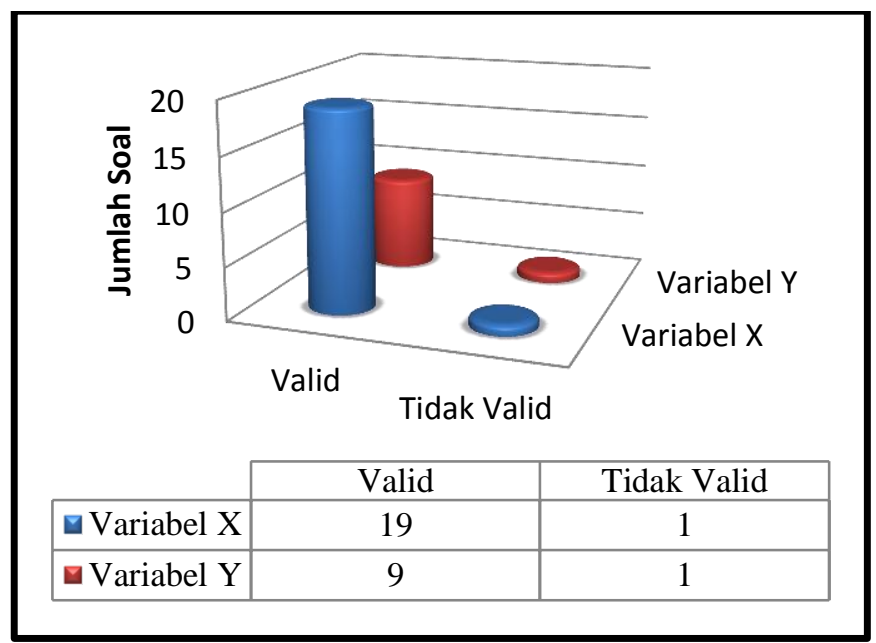

Gambar 1. Rekapitulasi Validitas Instrumen

\section{Deskripsi Data}

Data penelitian merupakan data mengenai penggunaan josheet interaktif dalam praktikum (variabel $\mathrm{X}$ ) dan data mengenai tingkat penguasaan siswa dalam praktikum MRLE (variabel Y).

Dari hasil perhitungan terdapat data variabel $\mathrm{X}$ sebagai berikut :

Tabel 1. Nilai Statistik Variabel X

\begin{tabular}{ccc}
\hline No & Statistik & Variabel X \\
\hline 1 & Jumlah sampel $(\mathrm{n})$ & 32 \\
2 & Jumlah data $\left(\sum \mathrm{X}\right)$ & 918 \\
3 & Skor tertinggi & 40 \\
4 & Skor terendah & 23 \\
5 & Rata-rata skor $(\bar{X})$ & 28,68 \\
6 & $\mathrm{~S}$ & 4,69 \\
\hline
\end{tabular}

Data variabel Y mengenai tingkat penguasaan siswa dalam praktikum MRLE diperoleh melalui penyebaran instrumen penelitian berupa tes objektif pilihan ganda sebanyak 17 item pertanyaan dan tes praktikum.

Dari hasil perhitungan terdapat data variabel Y tes objektif sebagai berikut : 
Tabel 2. Nilai Statistik Variabel Y

\begin{tabular}{ccc}
\hline No & Statistik & Variabel Y \\
\hline 1 & Jumlah sampel $(\mathrm{n})$ & 32 \\
2 & Jumlah data $\left(\sum \mathrm{X}\right)$ & 421 \\
3 & Skor tertinggi & 16 \\
4 & Skor terendah & 6 \\
5 & Rata-rata skor & 13,2 \\
6 & S & 2,29 \\
\hline
\end{tabular}

Selain dari tes obyektif yang berupa pilihan ganda, terdapat penilaian berupa tes praktikum yang meliputi kegiatan selama praktikum. Seperti persiapan, proses praktikum, sikap kerja dan laporan.

Dari hasil perhitungan terdapat data variabel Y praktikum sebagai berikut :

Tabel 3. Poligon Frekuensi Data Variabel Y

\begin{tabular}{ccc}
\hline No & Statistik & Variabel Y \\
\hline 1 & Jumlah sampel $(\mathrm{n})$ & 32 \\
2 & Jumlah data $\left(\sum \mathrm{X}\right)$ & 2325 \\
3 & Skor tertinggi & 80 \\
4 & Skor terendah & 62,5 \\
5 & Rata-rata skor & 72,65 \\
6 & S & 4,202 \\
\hline
\end{tabular}

\section{Uji Normalitas}

Uji normalitas dilakukan dengan menggunakan Chi-Kuadrat $\left(\chi^{2}\right)$. Penghitungan uji normalitas ini dihitung dengan menggunakan rumus Chi Kuadrat. Perhitung uji normalitas dari data variabel $\mathrm{X}$ dan variabel $\mathrm{Y}$ penulis menggunakan bantuan software Microsoft Office Excel 2007.

Tabel 4. Hasil perhitungan uji normalitas menggunakan chi-kuadrat

\begin{tabular}{cccc}
\hline Variabel & $\chi^{2}{ }_{\text {hitung }}$ & $\chi_{\text {tabel }}^{2}$ & Tafsiran \\
\hline $\mathrm{X}$ & 7,78 & 11,341 & Normal \\
$\mathrm{Y}$ & 6,220 & 13,277 & Normal \\
\hline
\end{tabular}

Data dikatakan berdistribusi normal apabila $\chi^{2}{ }_{\text {hitung }}<\chi_{\text {tabel }}^{2}$ dan tidak berdistribusi tidak normal apabila normal $\chi^{2}$ hitung $\geq \chi^{2}$ tabel dikatakan dari perhitungan 
variabel X dan variabel Y pada taraf kepercayaan 99\% dan derajat kebebasan 4 ternyata $\chi_{\text {hitung }}^{2}<\chi_{\text {tabel. }}^{2}$ Dengan demikian untuk pengolahan data selanjutnya dapat dilakukan dengan menggunakan statistik parametrik.

\section{Uji Linearitas dan Keberartian Regresi}

Hasil perhitungan persamaan regresi linear variabel $\mathrm{X}$ dan variabel $\mathrm{Y}$ diperoleh harga koefisien a sebesar 53,145 dan koefisien b sebesar 0,76 sehingga diperoleh persamaan regresi $\hat{Y}=53,145+0,76 X$. Berdasarkan persamaan tersebut diketahui bahwa jika tanpa adanya pengaruh dari variabel penggunaan jobsheet, hasil belajar siswa adalah sebesar 53,145 dan setiap kenaikan penggunaan jobsheet satu satuan maka hasil belajar siswa mengalami kenaikan sebesar 0,76.

Kemudian dari hasil pengujian linearitas bentuk regresi didapatkan harga $F_{\text {hitung }}=2,97$ dengan $F_{\text {tabel }}=3,37$ dan derajat kebebasan $\left(\mathrm{dk}_{(\mathrm{tc})}=10, \mathrm{dk}_{(\mathrm{G})}=20\right)$. Sesuai kriteria pengujian jika $F_{\text {hitung }}<F_{\text {tabel }}$ maka bentuk regresi linear dan jika $F_{\text {hitung }} \geq$ $\mathrm{F}_{\text {tabel }}$ maka bentuk regresi tidak linier, dengan hasil perhitungan dapat dinyatakan bahwa bentuk regresi variabel $\mathrm{X}$ dan variabel $\mathrm{Y}$ adalah linear.

Hasil pengujian keberartian regresi diperoleh harga $F_{\text {hitung }}=7,74$ dan harga $\mathrm{F}_{\text {tabel }}=7,56$ pada taraf nyata $99 \%$ dengan $\mathrm{dk}_{(\mathrm{b} / \mathrm{a})}=1$ dan $\mathrm{dk}_{(\mathrm{G})}=30$. Sesuai kriteria

pengujian jika $F_{\text {hitung }} \geq F_{\text {tabel }}$ maka koefisien arah berarti, jika $F_{\text {hitung }}<F_{\text {tabel }}$ maka koefisien arah tidak berarti, maka dapat dinyatakan bahwa persamaan regresi tersebut berarti pada taraf kepercayaan $99 \%$.

\section{Uji Koefisien Korelasi}

Analisis korelasi digunakan untuk mengetahui kekuatan (derajat) pengaruh antara variabel X (penggunaan jobsheet dalam praktikum MRLE) dengan variabel Y (tingkat penguasaan siswa dalam melaksanakan praktikum). Untuk perhitungannya menggunakan rumus korelasi Product Moment.

Dari hasil perhitungan koefisien korelasi diperoleh $r$ sebesar 0,45. Jika harga $r$ tersebut dimasukan kedalam penafsiran korelasi, maka nilai $\mathrm{r}$ ada pada rentang 0,400 
- 0,599. Dengan demikian besarnya korelasi $\mathrm{r}=0,45$ dapat ditafsirkan sebagai berikut:

a. Ada pengaruh antara variabel $\mathrm{X}$ terhadap variabel $\mathrm{Y}$.

b. Arah pengaruh positif.

c. Pengaruh antara variabel $\mathrm{X}$ dan variabel $\mathrm{Y}$ dikategorikan sedang

Setelah pengujian koefisien korelasi dilakukan dengan menggunakan rumus uji t, diperoleh harga $t_{\text {hitung }}=2,76$ pada taraf kepercayaan 99\% dengan $\quad d k=n-2$. Harga $t_{\text {hitung }}$ tersebut kemudian dikonsultasikan dengan harga $t_{\text {tebel }}$, dari $t_{\text {tabel }}$ diperoleh $\mathrm{t}=2,45$ Hasilnya $\mathrm{t}_{\text {hitung }}=2,76>\mathrm{t}_{\text {tabel }}=2,45$, maka dapat disimpulkan bahwa koefisien tersebut signifikan.

\section{PEMBAHASAN}

Berdasarkan analisis hasil sebaran angket, yang dilihat dari diagram distribusi frekuensi variable $\mathrm{X}$, menunjukan bahwa sebagian besar siswa masih merasa asing dengan jobsheet praktikum yang dikemas menjadi media interaktif. Kecendrungan data tersebut, tidak terlepas dari kondisi real yang dialami peserta didik selama praktikum. Dimana ada beberapa faktor yang dapat mempengaruhi kenyamanan dan suasana pembelajaran diantaranya:

1. Tidak tersedianya media komputer yang cukup untuk siswa, sedangkan jobsheet dengan media interaktif ini hanya bisa digunakan jika ada komputer. Komputer yang tersedia ada 17 unit, dan tidak semua siswa bisa mengoperasikan komputer sendiri-sendiri. Untuk menyiasati hal itu, satu unit komputer digunakan oleh dua orang siswa.

2. Peralatan praktikum yang kurang memadai. Ada beberapa perlatan praktikum, seperti power supply (sumber tegangan yang tidak bisa di gunakan), sehingga efektivitas kegiatan praktikum jadi berkurang.

Selain itu, penggunaan jobsheet interaktif ini mempunyai dampak positif untuk kegiatan belajar. Karena dapat merangsang siswa untuk belajar mandiri. Siswa lebih fokus belajar dan berinteraksi dengan jobsheet. Mencoba soal-soal yang tersedia 
di dalam jobsheet dan bisa langsung mengetahui hasil evaluasinya. Dengan begitu, kelas menjadi terkondisi dan tidak ribut.

Pengetahuan yang dimiliki peserta didik baik berupa pengetahuan teoritis maupun praktis menggambarkan tingkat penguasaan peserta didik tersebut terhadap kompetensi yang disyaratkan. Kesiapan aspek pengetahuan dalam menghadapi uji kompetensi merupakan hal penting yang harus dimiliki oleh setiap peserta didik yang akan mengikuti uji kompetensi. Kesiapan aspek pengetahuan dalam menghadapi uji kompetensi yang diukur dalam penelitian ini mencakup pengetahuan tentang identifikasi dioda, pengujian dioda, karakterisitik dan penerapan dioda.

Berdasarkan hasil analisis data menunjukan bahwa tingkat penguasaan siswa dalam melaksanakan praktikum dengan benar termasuk dalam kategori sedang. Kecenderungan data tersebut merupakan hasil dari nilai akhir variable Y yang terdiri dari tes obyektif (pilihan ganda) dan tes praktikum yang digunakan untuk menilai aspek afektif dan psikomotor siswa. Nilai tes praktikum mempunyai bobot $60 \%$ dan $40 \%$ untuk tes obyektif.

Berdasarkan perhitungan analisis data, maka terdapat hubungan antara penggunaan jobsheet interaktif ini dengan tingkat penguasaan siswa dalam melaksanakan praktikum dan juga terdapat pengaruh positif. Sekolah yang merupakan komponen penting dalam pendidikan, senantiasa berusaha untuk meningkatkan kualitas hasil belajar siswa melalui berbagai macam cara. Pengadaan dan pemenuhan sarana dan prasarana serta media pendidikan, peningkatan kualitas guru, dan yang tidak kalah pentingnya adalah peningkatan kualitas proses belajar mengajar itu sendiri. Peningkatan kualitas hasil belajar siswa tentunya dengan pemanfaatan hardaware (media) dan software (metode/langkah kerja) yang sesuai dengan tujuan mata pelajaran yang tercantum dalam kurikulum. 


\section{KESIMPULAN}

Berdasarkan dasar teori, hasil penelitian dan pengolahan data dapat di tarik kesimpulan bahwa :

1. Hasil perhitungan angket penggunaan jobsheet interaktif diperoleh angka $30 \%$ siswa sangat menyetujui adanya penggunaan jobsheet, $20 \%$ setuju dan menganggap jobsheet interaktif sebagai media pembelajaran yang menarik, $30 \%$ menganggap cukup menarik, $10 \%$ siswa berpendapat biasa saja, dan $1 \%$ siswa menganggap jobsheet interaktif pada praktikum MRLE tidak menarik dan tidak setuju dengan pemakaian jobsheet tersebut sebagai media pembelajaran. Respon siswa pada penggunaan jobsheet interaktif ini beragam. Jika melihat kondisi dan situasi kelas pada saat praktikum dilaksanakan, dengan penggunaan jobsheet ini siswa lebih fokus dan cenderung tidak ribut.

2. Hasil pengolahan nilai akhir siswa setelah dilakukan tes praktikum dan tes objektif pilhan ganda dimana sebelumnya digunakan media jobsheet interaktif dalam praktikum. Dari sampel 32 siswa, 18 siswa $(56,25 \%)$ memenuhi Kriteria Ketuntasan Minimal (KKM) dengan nilai akhir $\geq 75$. Sedangkan 14 siswa $(43,75 \%)$ belum memenuhi KKM yaitu mempunyai nilai akhir $\leq 75$. Terdapat banyak faktor yang mempengaruhi nilai akhir siswa dalam praktikum. Penggunaan jobsheet interaktif ini mempunyai kontribusi peningkatan nilai sebesar $20,25 \%$. Nilai tersebut didapat dari hasil perhitungan uji korelasi dan koefisien determinasi dari variabel $\mathrm{X}$ (penggunaan jobsheet interaktif dalam praktikum) dan variabel $\mathrm{Y}$ (tingkat penguasaan siswa dalam melaksanakan praktikum dengan benar).

\section{DAFTAR PUSTAKA}

Arikunto, S. (2010). Dasar-dasar Evaluasi Pendidikan. Jakarta: Bumi Aksara.

Arikunto, S.(1996). Prosedur Penelitian Suatu Pendekatan Praktik. Jakarta: Rineka Cipta.

Arikunto, S. (1998). Manajemen Penelitian. Jakarta: Rineka Cipta. 
Siregar, Syafaruddin. (2004). Statistik Terapan,Ed.1. Jakarta: Grasindo.

Sudjana, nana. (1992). Penilaian Hasil Proses Belajar Mengajar. Badan Usaha Jaya Press Jajasan Jaya Raya.

Sugiyono. (2010). Metode Penelitian Kuantitatif, Kualitatif dan $R \& D$. Bandung: Alfabeta.

Sugiyono. (2010). Statistika Untuk Penelitian. Bandung: Alfabeta. 